\section{Integrative Medicine \\ International}

\title{
Impact of Internet Addiction on Mental Health: An Integrative Therapy Is Needed
}

\author{
Anurag Tripathi \\ Ranchi College, Ranchi University, Ranchi, India
}

\section{Keywords}

Internet addiction - Internet gaming disorder - Attention deficit hyperactivity disorder .

Mindfulness $\cdot$ Reward circuitry

\begin{abstract}
In the past few years internet addiction (IA) and internet gaming disorder (IGD) have become very frequent, leading to many personality and psychiatric disorders including low self-esteem, impulsivity, poor sleep quality, mood disorder, and suicide. IA has been included in Appendix III of the Diagnostic and Statistical Manual for Mental Disorders (DSM-5) as IGD. In addition, IA leads to many neuroanatomical and neurochemical alterations including cortical thinning of various components of the brain and altered dopaminergic reward circuitry. Due to widespread neuropsychiatric and neurobiological implications of $I A$, multiple therapeutic approaches are needed. Integrative therapy in the form of yoga and mindfulness has proven to be effective in many addiction disorders including IA.

\section{Introduction}

The internet has become an integral part of modern day life, and the global population using the internet has grown to almost 3.8 billion [1]. Over the past few years, the study of the correlation between excessive internet use and mental disorders has grown. Young [2] first introduced the term internet addiction (IA) in a pioneering study and defined it as an impulse control disorder which does not involve an intoxicant. Thus, IA is a psychological dependence on the internet regardless of the type of activities pursued after logging in [3]. IA leads to an impairment of various life functions [4, 5]. Internet gaming disorder (IGD) is a consequence 
of IA, which is defined as uncontrolled internet gaming activity with negative impacts on the psychosocial functions [6]. The severity of IA and IGD is well established now, and in 2013 IA was included in Appendix III of the new version of the Diagnostic and Statistical Manual for Mental Disorders (DSM-5) as internet gaming disorder (IGD) [7]. Various diagnostic criteria for IA have been proposed $[2,8,9]$. Poor planning abilities, tolerance, impairment of control, and excessive online time were defined as the core symptoms. IA leads to many personality disorders [10-14].

Excessive internet use or IA and IGD are reported to be correlated with many psychiatric and psychosocial disorders that are reviewed in the present article. Structural alterations in internet-addicted brains and their implication have also been discussed. Integrative approaches such as yoga and mindfulness meditation have been proven to be effective as a de-addiction strategy to cure patients with IA.

\section{Comorbidity of Psychiatric Disorders in IA}

A lot of psychiatric disorders have been correlated with IA. It has been reported to be associated with low self-esteem [15], impulsivity [16], poor sleep quality [17], mood disorder [14], and suicide [18]. In an Indian context, a survey was conducted for IA which included 2,755 individuals (1,392 males and 1,363 females) in the age group of 18-65 years [19]. This study reported addiction in $1.3 \%$ individuals ( $2 \%$ males and $0.6 \%$ females). A study of 2,114 students (1,204 males and 910 females) diagnosed with IA using a self-report questionnaire revealed that individuals with IA had higher attention deficit hyperactivity disorder (ADHD) symptoms, depressive disorders, social phobia, and hostility particularly among male adolescents [20]. In another significant study regarding IA, four reliable and validated questionnaires were used: the young IA test, the insomnia severity index, the depression anxiety stress scale, and the Rosenberg self-esteem scale [21]. A total of 600 students (182 males and 418 females) aged between 18 and 28 years participated in this study. The potential IA prevalence rate was $16.8 \%$, and a significant difference was found between males and females with a higher prevalence in males (23.6 vs. $13.9 \%$ ). Furthermore, a strong correlation was found between IA and anxiety, stress, and depression [21]. Thus, the comorbidity of psychiatric disorders in IA is widely accepted.

\section{Structural and Chemical Alterations in Brain with IA}

It has been established in neuroimaging studies that IA is associated with structural and functional changes in brain regions involved in executive attention, decision making, emotional processing, and cognitive control [22]. Recently various morphometric studies on cortical centres of the brain with IA have found possible neural mechanisms. Brain regions which are involved in executive control, such as the orbitofrontal cortex, dorsolateral prefrontal cortex (dIPFC), and anterior cingulate cortex (Acc) showed decreased grey matter volume [23-26] and reduced cortical thickness $[27,28]$. In addition, cortical volume loss in striatum and insular cortex is also measured $[29,30]$. It has also been demonstrated in the internet-addicted brain that white matter integrity is impaired, and thus the proper connection and processing between the two hemispheres and connections among different lobes of the brain also get interrupted [22, 31]. Individuals with IA showed a larger volume in the hippocampus/ amygdala than healthy controls [32]. Dopamine transporter is a protein situated in the presynaptic terminal and is responsible for the active reuptake into the presynaptic neuron, thus playing a critical role in the regulation of striatal synaptic dopamine levels [33]. The 
Fig. 1. Normal neuronal circuitry in motivation-guided cognitive brain.

\begin{tabular}{l|l}
\hline DOI: 10.1159/000491997 & $\begin{array}{l}\text { @ } 2018 \text { The Author(s). Published by S. Karger AG, Basel } \\
\text { www.karger.com/imi }\end{array}$ \\
\hline
\end{tabular}

Tripathi: Impact of Internet Addiction on Mental Health: An Integrative Therapy Is Needed

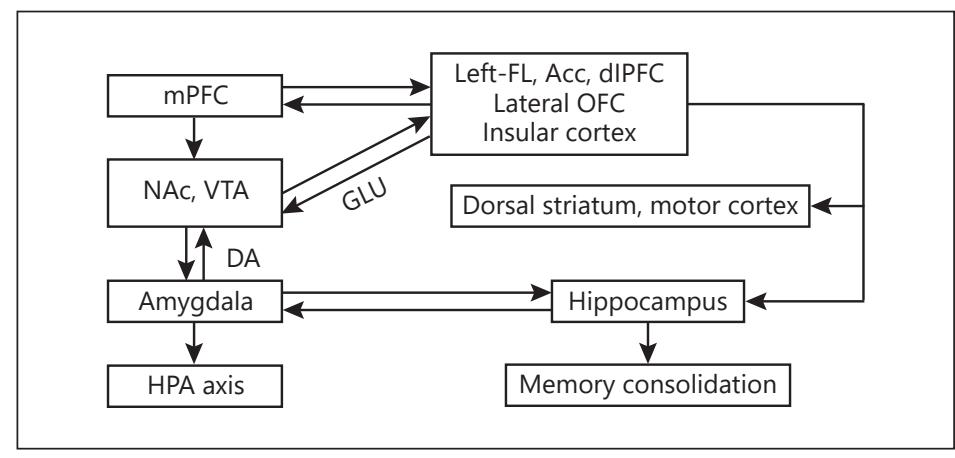

Fig. 2. Reward circuitry in addicted brain.

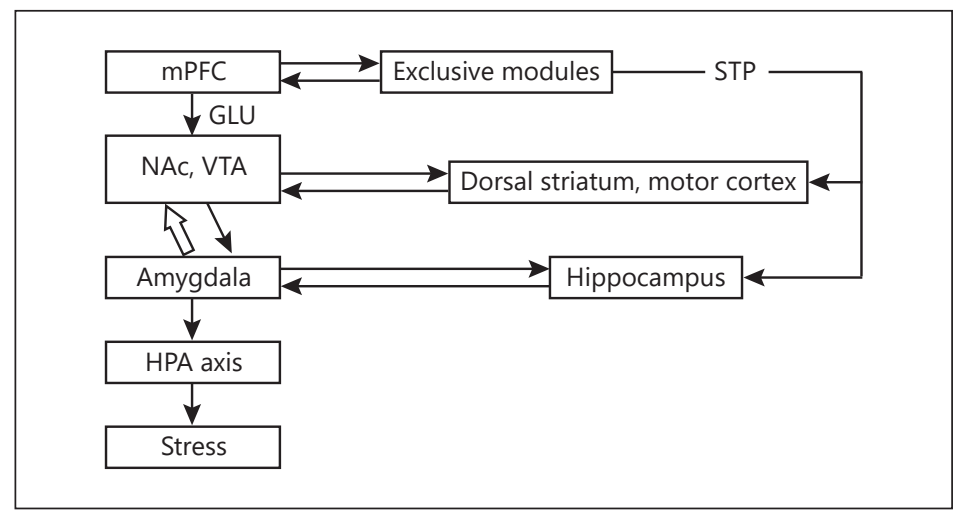

striatal dopamine transporter level was measured by single photon emission computed tomography in individuals with IA and brain scans were altered, and it was found that the dopamine transporter level of striatum was significantly decreased [34]. Further neuroimaging findings suggest that IA is associated with dysfunctions in the dopaminergic brain systems, and abnormalities in the dopaminergic neural system are similar in individuals with substance-related addiction [35].

\section{Altered Reward Circuitry in the Addicted Brain}

Studies based on positron emission tomography showed the direct role of dopamine in drug reward and addiction [36]. These findings also suggested the effect of addiction on motivation and executive functions of the brain. In the motivation-guided brain, there is an intricate but scrupulous neural circuitry connecting different executive and reward centres of the brain (Fig. 1). A conceived neuronal input through sense organs begins with the medial prefrontal cortex. After cortical processing, an electrochemical signal is sent to a set of highly interconnected neuronal areas including left frontal lobe, dlPFC, lateral orbitofrontal cortex, Acc, and insular cortex, which are the executive centres of brain responsible for goal-directed decision making [36]. Executive components of the brain transmit signals to striatum and motor cortex for decision-oriented movement. Further, these centres are connected to the hippocampus and amygdala for consolidation of memory. Moreover, medial prefrontal cortex is also connected with reward centres, ventral tegmental area, and nucleus accumbens (NAc). Internet gaming is associated with dopamine release similar in magnitude to that of drugs of abuse and lower dopamine transporter and dopamine $\mathrm{D}_{2}$ receptor occupancy indicating subsensitivity of dopamine reward mechanisms [37]. Decreases in $\mathrm{D}_{2}$ receptors in response 
to drugs are proportional to dopamine increases [38]. Dopamine is involved in motivation through its regulation of target regions including NAc, Acc, orbitofrontal cortex, dIPFC, amygdala, dorsal striatum, and ventral pallidum [39]. According to the model postulated by Volkow et al. [36], in addiction-dominated reward circuitry, ventral tegmental area, NAc, hippocampus, and amygdala get highly activated; in contrast, executive components including prefrontal cortex and Acc are less significant. Activated amygdala induces hypothalamic-pituitary-adrenal (HPA) axis which enhances the level of adrenaline and cortisol in blood and generates stress (Fig. 2). However, a well-organized executive neuronal circuitry is needed for proper goal-oriented functioning of the brain that gets distorted in any sort of addiction including IA.

\section{Integrative Approaches to Treat IA: Internet De-Addiction Programmes and Centres}

Due to many comorbid psychiatric disorders related to IA and its severe impact on human health, many integrative therapeutic approaches are being adopted as an alternative form of therapy. Among the psychotherapeutic interventions, the most frequently used approaches have been cognitive and behavioural therapy and motivational enhancement therapy [40]. In most of the strategies employed to cope with IA, a moderate and controlled use of the internet is promoted rather than total abstinence. In the abstinence model, addicts abstain from a specific internet application and use alternative applications [41]. Therapeutic strategies employed for internet addicts who have lost their social connections and family support would include cognitive restructuring regarding the specific internet applications, behavioural exercises, and exposure therapy in which the offline time of the individuals is enhanced by engaging them in socio-educational activities. Eight therapeutic strategies suggested by Young [42] are highly relevant for IA. These include: (1) practice the opposite, in which the pattern of internet use is disrupted by suggesting a new schedule; (2) external stoppers, in which clients are exposed to real life events by replacing the online activities; (3) setting goals, in which specific achievable goals are scheduled for clients; (4) abstinence from certain applications, in which the most attractive and uncontrollable application of the internet is encouraged for abstinence; (5) reminder cards are designed for clients to remind them of the benefits of breaking the addiction; (6) personal inventory, in which clients are encouraged to explore new activities that they have compromised at the cost of internet use; (7) support group for social interaction is provided; (8) family therapy, in which family interventions are encouraged to address relational problems that may have resulted from IA [43]. With the motivation enhancement therapy technique, an individualized treatment plan and an attainable goal are set with a collaborative, non-confrontational effort between the individual and the therapist [44]. The therapeutic relationship between client and expert is more like a partnership or companionship than an expert relationship to resolve the ambivalence. A webbased IA recovery facility has been designed (www.netaddiction.com) that provides e-counseling, on line support groups, tapes, and self-help books to cope with IA [43]. In Southeast Asian countries the adverse impact of IA has been taken seriously and has led to a series of studies and social work by the government and health care givers to curb and alleviate the problem [45]. India opened its first internet de-addiction centre in 2014 at the National Institute of Mental Health and Neurosciences (NIMHANS), Bengaluru, as a Service for Healthy Use of Technology (SHUT) centre [43]. After proper diagnosis, addicted patients particularly children and adolescents are given motivation enhancement therapy and psychoeducational training. Time management techniques and family sessions are also held. Stretching exercises to relax, games, yoga, and mindfulness meditation are also practiced as a de-addiction 
programme [44]. Likewise many specialized care giving programmes and treatment centres have been established in European countries including Germany and the UK (London) [45]. In Seattle the RESTART Internet Addiction Recovery Programme and in Pennsylvania the Digital Detoxification and Recovery Centre have been established [45]. In the RESTART programme, a community-based programme works with individuals, couples, and families to recognize the problematic use of the internet and an individualized programme is designed to promote a healthy, balanced life. Mentoring and coaching life skills, health and fitness exercise programmes, weekend adventure and recreational activities, and mindfulnessbased stress reduction programmes are few de-addiction strategies adopted by RESTART. The Korean government has framed a network of 190 IA counseling centres and hospitals. In Korea, the first specialist clinic for IA was established in 2011, where a 5-week treatment module is offered, which includes group sessions, art therapy, medication, neurofeedback, and transcranial magnetic stimulation [46]. China has more than 300 treatment centres that include behavioural training and medication for addicts like dancing, reading, sports, and elements from the 12-step programmes of the Alcoholic Anonymous along with family therapy [47]. The Japanese Ministry of Education has recognized the severity of IA, and it has started withdrawal camps for internet-addicted children [48]. However, these technology de-addiction centres and programmes based on an integrative approach are emerging worldwide.

\section{Yoga and Meditation as an Integrative Therapy for IA}

Among the integrative approaches to treat addiction, yoga and mindfulness have been proven as a potential complementary therapy. The therapeutic effects of yoga are widely studied concerning a multitude of various ailments and conditions including common symptoms of IA-like stress, anxiety, depression, and poor sleep quality. Therapeutic yoga is defined as the application of yoga postures and practices to the treatment of health conditions and involves instruction in yogic practices and teachings to prevent or reduce structural, physiological, emotional and spiritual pain, suffering or limitations [49]. In the western world yoga is now regarded as a holistic approach and is recognized by the National Institute of Health as a form of complementary and alternative medicine [50]. Yoga is a form of mindbody fitness involving a combination of muscular activity and internally focused awareness of the self, breath, and energy. In the western world, the most common aspects of yoga are the physical postures and breathing exercises of Hatha yoga and meditation [51]. The basic principle of yoga reveals that the human body is an integrative system of various interrelated and inseparable dimensions; thus, health or illness of one dimension affects the other dimensions. Moreover, healing comes from within and a greater sense of autonomy is achieved through yoga [49]. In the famous Indian scripture Yoga Sutras, Patanjali describes the eight limbs of yoga called ashtanga $[52,53]$. Based on the eight limbs of Patanjali, many yogic disciplines have been developed and each has its own technique for the treatment of diseases particularly stress-related ailments such as IA. Among the various forms of Hatha yoga, Iyengar yoga is highly studied and popular [50]. The breathing techniques of Hatha yoga focus on prolonged inhalation, breathing retention, and relaxation. Further, a homeostasis is maintained during the body posture between body system, breath, and concentration. Yoga practices enhance body flexibility and muscular strength, improved respiratory and cardiovascular function and overall well-being. Although direct studies regarding the efficacy of yoga in IA are scarce, a number of studies demonstrates the potential benefits of yoga practices on poor concentration, depression, anxiety, stress, and insomnia [49], which are the comorbid symptoms of IA. The common components of yoga include various postures or asana (body 
movements), conscious breathing, meditation, lifestyle and diet change, visualization and the use of sound [54]. Yoga promotes relaxation, lower breathing rate, focus on the present and inhibition of the sympathetic area of hypothalamus [55]. Consistent yoga practice improves depression, increases in serotonin levels, and decreases the levels of cortisol and monoamine oxidase [55]. In yoga, restorative postures, pranayama (breathing exercises), meditation, savasana (body in complete relaxation), and pratyahara (a turning inward of the senses) increase relaxation and improve sleep quality [49]. Mindfulness meditation has been found to be highly effective for the treatment of ADHD [56], one of the key psychiatric disorders related to IA $[19,20]$. Mindfulness meditation or mindfulness training (MT) is derived from Buddhist practices and is practiced as a type of focused, non-judgmental attention on purpose in the present moment and with non-judgmental acceptance. Basic elements of MT are intention, attitude, and attention [56]. For the therapeutic purposes, two types of meditation practices are well recognized: focused and receptive attention. In focused or concentrative meditation, the meditator focuses on a specific thought such as an image or a body sensation, disregarding the distracting events [57]. Mindfulness of breathing is a common practice in focused attention, where a participant is trained to focus on his/her breathing and sustain attention on the present moment. In receptive attention or open monitoring, the participant observes the content of his/her experience like sensations, thoughts, and emotions, from moment to moment without reaction. Thus, receptive attention improves self-regulation and impulse control, which is needed for the treatment of addictive behaviour including IA. A study was conducted on 24 adults and 8 adolescents with ADHD who were treated with 8 weeks of MT along with home assignments [58]. In this study participants started meditating for $5 \mathrm{~min}$ at a time, which was gradually increased to $30 \mathrm{~min}$. Each session comprised $2.5 \mathrm{~h}$ and was supplemented with daily home practice. The results were promising with78\% completing the study and $30 \%$ reporting a greater than $30 \%$ reduction in symptoms of ADHD. The authors concluded that an 8-week MT adapted for adolescents and adults with ADHD was feasible. Due to the lack of a control group, however, it was not clear whether the improvement was the result of MT or non-specific factors [56]. In another significant study on feasibility and acceptability of mindfulness meditation for adults with ADHD [59] a sample of 11 adults was studied and compared to a control group of 11 with MT. In this treatment group $63.6 \%$ also showed a 30\% reduction in ADHD symptoms compared to a $0 \%$ reduction in the control group in the self-rating scale. These studies show evidence of acceptability and feasibility in MT [59]. Studies on the brain activation before and after variable periods of MT using fMRI have shown that during MT attention-related cortices such as the prefrontal cortex and Acc get activated [60].

In a significant review by Khanna and Greeson [61] on yoga and mindfulness as complementary therapies for addiction, it is suggested that the skill, insights, and self-awareness through yoga and mindfulness practices can target multiple psychological, neural, physiological, and behavioural processes implicated in addiction and relapse. Moreover, in a review [61], various meditation-based training programmes which are effectively employed for the treatment of various addictions, such as mindfulness-based relapse prevention, MT for smoking cessation, and mindfulness-oriented recovery enhancement, have been properly described. Mindfulness-based relapse prevention is an 8-week manualized programme which incorporates cognitive-behavioural skills with mindfulness-based practices to decrease relapse by increasing awareness [62]. Since IA has the same implications as other forms of addictions, it has been suggested that the efficacy of various forms of yoga, meditation, and MT as an integrative medicine is feasible. Thus, yoga and meditation should be treated as a complementary therapy for medical therapy in the treatment of stress, anxiety, depression, and other psychiatric addictive disorders such IA, since it increases self-confidence, mind relaxation, and attentiveness, and decreases irritability. 
Tripathi: Impact of Internet Addiction on Mental Health: An Integrative Therapy Is Needed

\title{
Disclosure Statement
}

\author{
The author has no conflict of interest to reveal.
}

\section{References}

1 Internet World Statistics. 2017. www.internetworldstats.com (accessed June 2017).

2 Young KS: Caught in the Net: How to Recognize the Signs of Internet Addiction and a Winning Strategy for Recovery. New York, Wiley, 1998.

3 Kim K, Lee H, Hong JP, Cho MJ, et al: Poor sleep quality and suicide attempt among adults with internet addiction: a nationwide community sample of Korea. PLoS One 2017;12:e174619.

4 Griffith M: Internet addiction. Psychologist 1999;12:245-250.

$5 \mathrm{Ko} \mathrm{CH}$, Yen JY, Chen CC, et al: Tridimensional personality of adolescents with internet addiction and substance use experience. Can J Psychiatry 2006;51:887-894.

6 Ko CH: Internet gaming disorder. Curr Addict Rep 2014;1:177-185.

7 Block JJ: Issues for DSM-V: internet addiction. Am J Psychiatry 2008;165:306-307.

8 Young KS: Internet addiction: the emergence of a new clinical disorder. Cyberpsychol Behav 2009;1:237-244.

9 Widyanto L, Griffith MD, Brunsden V: A psychometric comparison of the internet addiction test, the internet related problem scale and self-diagnosis. Cyberpsychol Behav Soc Netw 2011;14:141-150.

10 Dalbudak E, Everen C, Aldemir S, Everen B: The severity of internet addiction risk and its relationship with the severity of borderline personality features, childhood traumas, dissociative experiences, depression and anxiety symptoms among Turkish University students. Psychiatry Res 2014;219:577-582.

11 Kim EJ, Namkoong K, Ku T, Kim SJ: The relationship between online game addiction and aggression, selfcontrol and narcissistic personality traits. Eur Psychiatry 2008;23:212-218.

12 Floros G, Siomos K, Stogiannidou A, Giouzepas I, Garyfallos G: The relationship between personality, defence styles, Internet addiction disorder and psychopathology in college students. Cyberpsychol Behav Soc Netw 2014;17:672-678.

13 Floros G, Siomos K, Stogiannidou A, Giouzepas I, Garyfallos G: Comorbidity of psychiatric disorders with internet addiction in a clinical sample: the effect of personality, defence style and psychopathology. Addict Behav 2014;39:1839-1845.

14 An J, Sun Y, Wan Y, Chen J, Wang X, Tao F: Associations between problematic internet use and adolescents' physical and psychological symptoms: possible role of sleep quality. J Addict Med 2014;8:282-289.

15 Naseri L, Mohamadi J, Sayehmiri K, Azizpoor Y: Perceived social support, self-esteem and internet addiction among students of Al-Zahra University, Tehran, Iran. Iran J Psychiatry Behav Sci 2015;9:e421.

16 Lee HW, Choi JS, Shin YC, Lee JY, Jung HY, Kwon JS: Impulsivity in internet addiction: a comparison with pathological gambling. Cyberpsychol Behav Soc Netw 2012;15:373-380.

17 Kim JH, Lau CH, Cheuk KK, Pan P, Hui HL, Griffiths SM: Brief report: predictors of heavy internet use and associations with health promoting and health risk behaviours among Hong Kong University students. J Adolesc 2010;33:215-220.

18 Kim K, Rye E, Chone MY, Yeun EJ, Choi SY, Seo JS, et al: Internet addiction in Koran adolescents and its relation to depression and suicidal ideation: a questionnaire survey. Int J Nurs Stud 2006;43:185-192.

19 Sharma MK, Rao GN, Benegal V, Thennarasu K, Thomas D: An emerging concern for raising awareness and promotion of healthy use of technology. Indian J Psychol Med 2017;39:495-499.

20 Yen JY, Ko CH, Yen CF, Wu HY, Yand MJ: The comorbid psychiatric symptoms of internet addiction: attention deficit hyperactivity disorder, depression, social phobia, and hostility. J Adolesc Health 2007;41:93-98.

21 Younes F, Halawi G, Jabbour H, Osta NE, et al: Internet addiction and relation with insomnia, anxiety, depression, stress and self-esteem in university students: a cross section designed study. PLoS One 2016;11:e0161126.

22 Lin F, Yan Z, Yasong D, Lindi Q, et al: Abnormal white matter integrity in adolescents with internet addiction disorder: a tract based spatial statistics study. PLoS One 2012;7:e30253.

23 Weng CB, et al: Grey matter and white matter abnormalities in on line game addiction. Eur J Radiol 2013;82: 1308-1312.

24 Jin C, et al: Abnormal prefrontal cortex resting state functional connectivity and severity of internet gaming disorder. Brain Imaging Behav 2016;10:719-729.

25 Lin X, Dong G, Wang Q, Du X: Abnormal grey matter and white matter volume in internet gaming addicts. Addict Behav 2015;40:137-143.

26 Wang $\mathrm{H}$, et al: The alteration of grey matter volume and cognitive control in adolescents with internet gaming disorder. Front Behav Neurosci 2015;9:64.

27 Hong SB, et al: Reduced orbitofrontal cortical thickness in male adolescents with internet addiction. Behav Brain Funct 2013;9:11.

28 Yuan K, et al: Cortical thickness abnormalities in late adolescence with internet addiction. PloS One 2013; 8:e53055.

29 Weng CB, Qian RB, Xian-Ming F, Bin L, et al: Gray matter and white matter abnormalities in on line game addictions. Eur J Radiol 2013;82:1308-1312. 
Tripathi: Impact of Internet Addiction on Mental Health: An Integrative Therapy Is Needed

30 Chen CY, Yen JY, Wang PW, et al: Altered functional connectivity of the insula and nucleus accumbens in internet gaming disorder. Eur Addict Res 2016;22(4):192-200. DOI: 10.1159/000440716.

31 Weng CB, Qian RB, Xian-Ming F, Bin L, et al: Gray matter and white matter abnormalities in on line game addictions. Eur J Radiol 2013;82:1308-1312.

32 Yoon EJ, et al: Altered hippocampus volume and functional connectivity in males with internet gaming disorder. Sci Rep 2017;7:5744.

33 Kim SH, Baik SH, Park CS, Kim SJ, Choi SW, Kim SE: Reduced striatal dopamine $\mathrm{D}_{2}$ receptors in people with internet addiction. Neuroreport 2011;22:407-411.

34 Hou H, Jia S, Hu S, Fan R, et al: Reduced striatal dopamine transporters in people with internet addiction disorders. J Biomed Biotechnol 2012;2012:1-5. DOI: 10.1155/2012/854524.

35 Volkow ND, Fowler JS, Wang GJ, Baler R, Telang F: Imaging dopamine's role in drug abuse and addiction. Neuropharmacology 2009;56:3-8.

36 Volkow ND, Wang GJ, Fowler JS, Tomasi D, Telang F: Addiction: beyond dopamine reward circuitry. PNAS 2011;108:15037-15042.

37 Weinstein A, Livny A, Weizman A: New developments in brain research of internet and gaming disorder. Neurosci Behav Rev 2017;75:314-330.

38 Breier A, et al: Schizophrenia is associated with elevated amphetamine induces synaptic dopamine concentrations: evidence from a novel positron emission tomography method. Proc Natl Acad Sci USA 1997;94:2569_ 2574.

39 Salamone JD, Correa M, and Farrar A, Mingote SM: Effort related functions of nucleus accumbens dopamine and associated forebrain circuits. Psychopharmacology (Berl) 2007;191:461-482.

40 Wieland DM: Computer addiction: implications for nursing psychotherapy practice. Perspect Psychiatr Care 2005;41:153-161.

41 Murali V, George S: Lost online: an overview of internet addiction. Adv Psychiatr Treat 2007;13:24-30.

42 Young KS: Internet addiction: symptoms, evaluation and treatment; in Van de Creeek L, Jackson T (eds): Innovations in Clinical Practice: A Source Book. Florida, Professional Resource Press, 1999, pp 19-31.

43 Sharma MK, Palanichami TS: Psychological interventions for technical addictions. Indian J Psychiatry 2018; 60:541-545.

44 Sharma MK, Mahindru P: Video game addiction: impact on teenager's life style. Natl Med J India 2015;28: 282-285.

45 Mok JY, Choi SW, Kim DJ, Choi JS, et al: Latent class analysis on internet and smartphone addiction in college students. Neuropsychiatr Dis Treat 2014;10:817-828.

46 Ahn DH: Korean policy on treatment and rehabilitation for adolescents' internet addiction. International Symposium on the Counseling and Treatment of Youth Internet Addiction. Seoul, National Youth Commission, 2007, p 49.

47 You-Sun N: Internet addicts get help in S. Korea. The China Post. 2011. www.chinapost.com.tw/life/scienceand -technology/2011/06/20/306789/Internet addicts.htm.

48 Majumdar A: Japan plans fasting camps for web addicted children. Tech2.2013.www.tech2.in.com/news/ general/japan-plans-fasting-camps-for-webaddicted-children/912284.

49 Woodyard C: Exploring the therapeutic use of yoga and its ability to increase the quality of life. Int J Yoga 2011; 4:49-54.

50 Williams K, Steinberg L, Petronis J: Therapeutic application of lyenger yoga for healing chronic low back pain. Int J Yoga Ther 2003;13:55-67.

51 Collins C: Yoga: intuition, preventive medicine and treatment. J Obstet Gynecol Neonatal Nurs 1998;27:563571.

52 Lasaster J: The heart of patanjali. Yoga J 1997;137:134-144.

53 Maehle G: Ashtanga Yoga: Practice and Philosophy. Analoo City, Kaivalya Publications, 2006.

54 Desikachar K, Bragdon L, Bossart C: The yoga of healing: exploring yoga's holistic model for health and wellbeing. Int J Yoga Ther 2005;15:17-39.

55 McCall T: Yoga as a Medicine. New York, Bantam Dell, Random House Inc, 2007.

56 Modesto-Lowe V, Farahmand P, Sarro L: Does mindfulness meditation improve attention in attention deficit hyperactivity disorder? World J Psychiatry 2015;5:397-403.

57 Holzel BK, Ott U, Hempel H, Hackl A, Wolf K, Stark R, Vaitl D: Differential engagement of anterior cingulated and adjacent medial frontal cortex in adept meditators and non-meditators. Neurosci Lett 2007;421:16-21.

58 Zylowska L, Smalley SL, Schwartz JM: Mindful awareness and ADHD; in Didonna F (ed): Clinical Handbook of Mindfulness. New York, Springer, 2009, pp 319-338.

59 Mitchell JT, McIntyre EM, English JS, Dennis MF, Beckham JC, Kollins SH: A pilot trial of mindfulness meditation training for ADHD in adulthood: impact on core symptoms, executive functioning, and emotional dysregulation. J Atten Disord 2017;21(3):1105-1120.

60 Chaisa A, Serretti A: Mindfulness based cognitive therapy for psychiatric disorders: a systematic review and meta-analysis. Psychiatry Res 2011;187:441-453.

61 Khanna S, Greeson JM: A narrative review of yoga and mindfulness as complimentary therapies for addiction. Complement Ther Med 2013;21:244-252.

62 Collins C: Yoga: intuition preventive medicine and treatment. J Obstet Gynecol Neonatal Nurs 1998;27:563568. 